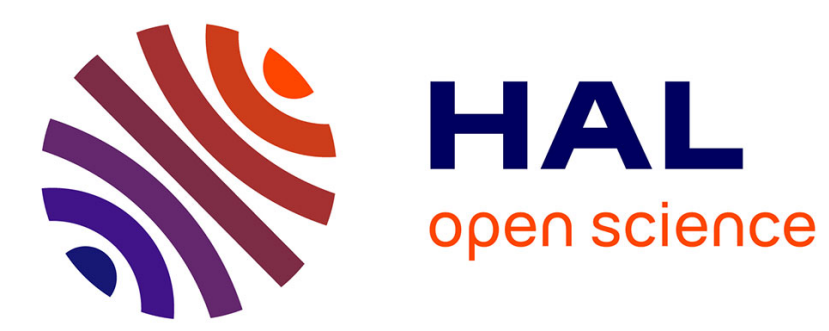

\title{
Economic Science and Political Influence
}

Gilles Saint-Paul

\section{To cite this version:}

Gilles Saint-Paul. Economic Science and Political Influence. 2012. halshs-00759057

\section{HAL Id: halshs-00759057 \\ https://shs.hal.science/halshs-00759057}

Preprint submitted on 29 Nov 2012

HAL is a multi-disciplinary open access archive for the deposit and dissemination of scientific research documents, whether they are published or not. The documents may come from teaching and research institutions in France or abroad, or from public or private research centers.
L'archive ouverte pluridisciplinaire HAL, est destinée au dépôt et à la diffusion de documents scientifiques de niveau recherche, publiés ou non, émanant des établissements d'enseignement et de recherche français ou étrangers, des laboratoires publics ou privés. 


\section{PARISSCHOOL OF ECQNOMICS}

WORKING PAPER N²012 - 41

\section{Economic Science and Political Influence}

Gilles Saint-Paul

JEL Codes : A11, E6

Keywords: Ideology ; Macroeconomic Modelling ; Self-con.rming equilibria ; Polarization ; Autocoherent Models ; Intellectual Competition ; Degenerative Research Programs ; Identification

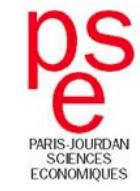




\title{
Economic Science and Political Influence
}

\author{
Gilles Saint-Paul*
}

November 27, 2012

\begin{abstract}
When policymakers and private agents use models, the economists who design the model have an incentive to alter it in order infuence outcomes in a fashion consistent with their own preferences. I discuss some consequences of the existence of such ideological bias. In particular, I analyze the role of measurement infrastructures such as national statisticall institutes, the extent to which intellectual competition between different schools of thought may lead to polarization of views over some parameters and at the same time to consensus over other parameters, and finally how the attempt to preserve influence can lead to degenerative research programs.

JEL: A11, E6

Keywords: Ideology, Macroeconomic modelling, Self-confirming equilibria, polarization, autocoherent models, intellectual competition, degenerative research programs, identification

${ }^{*}$ Paris School of Economics, New York University Abu Dhabi and Toulouse School of Economics. This paper is the text of my EEA Congress Schumpeter Lecture, Malaga, August 2012. I am grateful to the President of the EEA, Jordi Gali, for giving me the opportunity to present this work at the congress. This research has benefitted from comments from seminar participants at Princeton, Yale, CERGE, Venice University, Toulouse School of Economics, the European Summer Symposium in Macroeconomics 2011, Gerzensee, and the International Seminar on Macroeconomics 2011, Malta.
\end{abstract}




\section{Introduction}

In the standard approach to political economy, agents differ in their preferences. These preferences in turn are aggregated by some political mechanism, which leads to public decisions being made. From such a perspective, an interest group can influence outcomes only by acquiring more weight in the political process, for example through campaign contributions.

Yet another important element is the debate on the actual effects of policies. We observe that people differ in their beliefs about how policies relate to outcomes, because there exists no firm, agreed upon theory that would pin down those mechanisms. This in turn opens the door for interest groups to participate in the debate so as to influence beliefs in a self-serving fashion. It then follows that, in addition to politicians, another class of people will naturally play a key role in public decision making: the intellectuals. In particular, given that arguably most decisions made by governments are economic in nature - from aggregate demand management down to pricing of public utilities, allocating health expenditure, or the cost-benefit analysis of public works - we expect a prominent role to be ascribed to economists.

Controversies about how the economy works have important consequences for which policies should be prescribed. And one may like such policies more or less, not only because of one's beliefs about how they work, but also due to one's preferences or self-interest.

For example, how much the government should be involved in macroeconomic management depends on certain properties of the economy: Is there slack, or are resources fully utilized? Are expectations adaptive or rational? Are fluctuations chiefly driven by supply shocks or demand shocks? Is the Keynesian multiplier high or low? The extent to which the economy will be macro-managed by the government depends on the answers one gives to those questions. That is, they depend on the theory, in a way tyically summarized in 
Table 1. Depending on one's tastes for government intervention, then, one may favor one theory or another. ${ }^{1}$

\section{[TABLE 1 HERE]}

Consider another example: Should there be a minimum wage, and how high should it be? Again, the answer depends on our views on the functioning of the labor market. We are more likely to be in favor of high minimum wages if we believe firms have monopsony power (and that is the main thrust of Card and Krueger's (1994) new economics of the minimum wage), because then wages are below the marginal product of labor and jobs won't be destroyed if they go up, and if we think the elasticity of labor demand is low, because then minimum wages entail a low cost in terms of foregone jobs. Furthermore, minimum wages clearly have distributive consequences, so that some social groups will favor them and others oppose them ${ }^{2}$. Clearly, the former will benefit if more people hold views like those in the first column of Table 2 , because such views are likely to lead to policy choices in favor of a high minimum wage.

[TABLE 2 HERE]

Real world examples of views of the world being polarized along ideological lines are common. We may mention the recent US controversy about the size of the Keynesian multiplier, where more conservative economists aligned with the former Republican administration argued that the multiplier was low, while those aligned with the Democratic party considered it was high. Similarly, in France the labor unions protested against the publication in the national statistican institute journal of a study (Laroque and Salanié, 2000) which concluded

\footnotetext{
${ }^{1}$ Throughout this paper I will assume that agents have instrinsic tastes for the level of government intervention. This could be interpreted as deeper beliefs regarding the nature and efficacy of government, but it can also be interpreted as a short cut for the welfare of special interests, that is, people whose economic activity is more dependent on government involvement in the economy will benefit more from such involvement.

${ }^{2}$ At least this will be the case if no other, more efficient fiscal instrument can be used for the benefit of the winners of such policies. See Acemoglu and Robinson (2001) and Saint-Paul (2000).
} 
that hundreds of thousands of jobs were lost because of the minimum wage, while promoting alternative studies which did not reach such conclusions. Yet we also observe, in addition to polarization, some degree of agreement, often after a convergence process over time. We would like to explain why there is more consensus on some aspects of the model than others, in light of our view that beliefs are shaped by self-interest.

\section{Influencing outcomes through beliefs}

I now turn to the question of how experts can influence outcomes. A charismatic guru could in principle promote a view of the world which is demonstrably false and yet wield influence. But here we are talking about scientists and we must impose discipline upon the set of theories that they may formulate. In physics, all competing theories, including the correct one, must be observationally equivalent, otherwise some would be rejected by the data. In economics, things are more complex because beliefs affect outcomes through the formation of expectations by private agents and the design of government policies, which is precisely the source of the intellectuals' political power ${ }^{3}$. In other words, the data themselves depend on which model is believed by the agents. Nevertheless, it makes sense to impose the restriction that any perceived model must match those data. This means that the economy must be in a self-confirming equilibrium (SCE, as in Fudenberg and Levine $(1993,2007)$ ) where beliefs may be incorrect but are nevertheless confirmed in equilibrium. Only a deviation from the equilibrium path would reveal that beliefs are wrong. In the context I am dealing with here, to support such an SCE, the model must be autocoherent: If everybody uses it to form their expectations, then it matches the corresponding equilibrium probability distribution of the observables ${ }^{4}$.

\footnotetext{
${ }^{3}$ MacKenzie (2008) documents the performative aspects of economic theory in the financial sector.

${ }^{4}$ See Saint-Paul (2012a) for an exploration of the properties of those models.
} 
This means that the model is observationally equivalent to the correct model in the equilibrium where people use it. Figure 1 illustrates this concept. Suppose that the model consists of two parameters, $a$ and $b$. In general people may believe that the values of those parameters are $\hat{a}$ and $\hat{b}$, which may differ from their correct values. On figure 1 , the correct model is represented by point CM while point " 1 " represents an alternative, incorrect model. The locus $\operatorname{IM}(1)$ is the set of "identified" models in the equilibrium where people use model 1 to form their expectations. This locus contains more than one point, which means that the model is under-indentified; of course the correct model CM explains the data in any equilibrium, so it lies on $\operatorname{IM}(1)^{5}$. As drawn, locus $\operatorname{IM}(1)$ goes through 1. This means that this equilibrium is self-confirming, i.e. that the model is autocoherent. We can draw the locus of autocoherent models AC, i.e. the set of models $X$ such that $X \in I M(X)$. As long as AC is not reduced to $\mathrm{CM}$, there exist self-confirming equilbria supported by incorrect beliefs about the way the economy works. Again that is possible because the model is under-identified.

Note that in that equilibrium, model 2 is also observationally equivalent to model 1 (and to the correct model). Therefore, an economist could credibly claim that it is correct. But if people were to believe him, they would act differently and the equilibrium would change. In that new equilibrium, the set of identified models is now $\operatorname{IM}(2)$ instead of $\operatorname{IM}(1)^{6}$. Since point 2 is not on $\operatorname{IM}(2)$, model 2 is not autocoherent. It is self-defeating: the data would reject it

\footnotetext{
${ }^{5}$ Here we need to be more precise: what explains the data in any equilibrium such as 1 is the correct model of how the economy works conditional on expectations formation and policy choices, supplemented with the correct description of expectations formation and policy choices in that equilibrium, i.e. supplemented with the correct assumption that people use the incorrect perceived model to make choices.

On the other hand, a model is autocoherent if the (incorrect) assumption that it describes the behavior of the economy conditional on policies and expectations formation, along with the assumption that it is used to form expectations and policies, explains the data, in an equilibrium where it is indeed used to form expectations and policies - implying that the second assumption is correct.

Implicitly, when one moves along the IM(1) locus, it is common knowledge that people use the perceived model 1. Therefore, a point along that locus is a model which explains the data in equilibrium 1 , under the joint assumption that it is the correct one and that people use model 1 to form expectations and policies.

${ }^{6}$ Since $\mathrm{CM}$ is the correct model, it explains the data in all equilibria. Therefore CM is on the $\operatorname{IM}(2)$ locus as well.
} 
if everybody believed it. An economist promoting model 2 remains scientifically credible only as long as people do not believe him. Finally, for the sake of completeness, we may also consider the set of models that are economically equivalent to model 1 . That is the set of models that would deliver the same equilibrium if people believed them. It is drawn as $\mathrm{EE}(1)$ on figure 1. Model 3 is on $\mathrm{EE}(1)$ and delivers the same equlibrium if people use it rather than model 1 , but in that equilibrium, the set of models that describe the observables is given by $\operatorname{IM}(1)$, and since model 3 does not lie on that locus it is again not autocoherent ${ }^{7}$.

The preceding literature has produced some important examples of such selfconfirming equilibria. Piketty (1995) studies a model of income inequality and redistribution where people may believe either that "luck" is the key determinant of income, or that "effort" is the important variable. Any of those two beliefs is self-confirming because of its policy consequences. In the "luck" equilibrium, people vote for a high level of redistribution; effort is then low and so is the share of income inequality explained by effort, which validates the belief that luck matters more. The opposite holds in the other equilibrium ${ }^{8}$.

Sargent (2008) studies a situation where the policy maker has some beliefs regarding the (local) slope of the output/inflation trade-off. These beliefs make it optimal to select a given point on that trade-off, which is the equilibrium point of the economy. As long as the economy remains at that point (and since it is supposedly optimal, there is no reason to deviate from it), the slope of the Phillips curve is unobserved. Consequently the initial beliefs about its slope are

\footnotetext{
${ }^{7}$ As discussed in Saint-Paul (2012b, 2012c), if people have to form expectations of observable variables and the rational expectations equilibrium (REE) is unique, instead of a model people can just use the relevant moments to form their expectations and this is enough for the economy to be at the REE. All autocoherent models are then economically equivalent to the correct one and there is no scope for the expert to influence outcomes.

This is a situation where the reduced form model is enough to form one's expectations. Lucas and Sargent (1979) argue that in practice that is unlikely to be the case as far as the policymaker is concerned. Hence the utmost importance of the identifying assumptions underlying structural identification of the parameters.

${ }^{8}$ This mechanism has then been re-examined by Benabou and Ok (2001), Alesina and Angeletos (2005).
} 
unchanged and the equilibrium is self-confirming.

What is missing from those examples is a positive theory of which perceived model is actually used. My objective is to lay the steps for such a theory ${ }^{9}$. In the next section I will lay out a simple model of macro stabilization policy that has been fully analyzed in Saint-Paul (2012b), and which delivers some plausible predictions on how an economist's ideological bias would influence his models. I will then extend it to study some aspects of the interplay between political economy and the evolution of scientific paradigms. That is, in a world of self-interested experts seeking to achieve influence so as to make the world more palatable to their tastes, how do we expect science to evolve? I will in particular address the following questions:

- How do theory and measurement interact? How many resources will be spent on measurement, and is this amount right? How will theory react to the accuracy of measurement?

- What are the effects of intellectual competition between several school of thoughts? Do we expect polarization or consensus?

- How will experts try to preserve influence when new data are inconsistent with their model? How will the theory evolve in response to such events?

\section{The self-interested expert: A simple macro- economic example}

I now briefly discuss a variant of the model studied in Saint-Paul (2012b) which is useful to illustrate the optimal choice of a perceived model by a self-interested

\footnotetext{
${ }^{9}$ For Marxists such as Lucaks and Gramsci, ideology necessarily reflects the interests of the "dominant class". Yet this ignores that this "dominant class" is heterogeneous. Exporters and importers have conflicting interests, and similarly for savers who hold nominal bonds and fear inflation vs. bankers who want credit to flow as free as possible.

Furthermore, in a democratic society, competition for devising the "dominant" ideology is open. There is no presumption that the dominant ideology will be that of the dominant class, unless we specify how the dominant class achieves intellectual domination. Clearly Hayek (1949) believed that intellectual domination did not coincide with economic domination.
} 
expert facing autocoherence constraints.

I consider an economy where the government attempts to stablize aggregate demand shocks. As those are not directly observed, it needs to make inferences and for this it will use a "perceived model". The perceived model is determined by an expert who is fully believed by the government. In particular there is no scope for the government to reverse engineer the statements of the expert, contrary to the cheap talk literature (Crawford and Sobel, 1982). This is because the government knows neither the expert's preferences and is incapable of forming priors with respect to the correct model.

The government's objective is the following:

$$
\min E\left(y^{2}+\varphi g^{2}\right)
$$

where $y$ is a measure of GDP and $g$ a measure of government spending. The greater the parameter $\varphi$, the more reluctant the government is to use active stabilization policy. It is therefore natural to interpret governments with a higher value of $\varphi$ as being more conservative.

The equilibrium of the economy is determined by the following two equations:

$$
\begin{aligned}
& y=a g+u+v, \\
& z=\omega u+\varepsilon .
\end{aligned}
$$

The first equation can be interpreted as an aggregate demand curve. The variables $u$ and $v$ are two independent, normally distributed shocks with zero means and variances $\sigma_{u}^{2}$ and $\sigma_{v}^{2}$. I will label $u$ a "demand shock" and $v$ a "supply shock". The parameter $a$ is the response of output to government expenditures. It is natural to call it the "Keynesian multiplier". The second equation determines $z$, a signal that the government observes prior to setting the level of expenditure $g$. This signal has noise $\varepsilon$, which has a zero mean, is normally distributed, independent of $u$ and $v$ and has a variance equal $\sigma_{\varepsilon}^{2}$. The parameter 
$\omega$ describes how sensitive the signal is to the demand shock. The greater $\omega$, the better the signal.

The preceding equations describe how the economy is objectively working. That disturbances have a zero mean and are independent is common knowledge. The correct model can be summarized as a quintuple $\left(a, \omega, \sigma_{u}^{2}, \sigma_{v}^{2}, \sigma_{\varepsilon}^{2}\right)$. In what follows I will normalize the correct values of $\omega$ and $\sigma_{u}^{2}$ to $\omega=\sigma_{u}^{2}=1$.

Instead of the correct model, the government uses a perceived model which has the same specification as the correct one but may have different parameter values. For reasons that will be clear later, I will assume that the value of $\sigma_{\varepsilon}^{2}$ is common knowledge. Therefore the perceived model can be described as a quintuple $\left(\hat{a}, \hat{\omega}, \hat{\sigma}_{u}^{2}, \hat{\sigma}_{v}^{2}, \sigma_{\varepsilon}^{2}\right)$, where, throughout the text, hats will denote perceived values. Since the correct value of $\sigma_{\varepsilon}^{2}$ is common knowledge, it appears without a hat.

The perceived model is set by an economist who (i) knows the correct model but chooses to report a potentially incorrect one, (ii) has preferences that may differ from those of the government, and (iii) can only choose an autocoherent model, otherwise the economy could not be in a SCE, as the model would be invalidated by the data. Thus, as illustrated on figure 2 in the two dimensional case, the economist picks his most preferred perceived set of parameters so as to maximize his utility function subject to the autocoherence constraints. Here I will assume that the economist's objective is

$$
\min E\left(y^{2}+\bar{\varphi} g^{2}\right)
$$

Therefore, the economist is more (resp. less) conservative than the government if and only if $\bar{\varphi}>\varphi$ (resp. $\bar{\varphi}<\varphi$ ).

[FIGURE 2 HERE]

It is interesting to note that this same simple model could be given a totally different interpretation and thus applied to a different kind of policy decision. 
For example we could interpret $g$ as an indicator negatively related to the minimum wage (such as $-\ln w$ if $w$ denotes the minimum wage), $a$ as the absolute value of the relevant elasticity of labor demand, and $y$ as the level of unskilled employment. In such a world, the greater $\varphi$, the more the government prefers stable wages over stable employment, which may be interpreted as being more favorable to unions ${ }^{10}$.

To solve this model, we need to derive optimal government policy, then we need to compute the autocoherence constraints, and finally we need to solve for the economist's optimal perceived model.

\subsection{Optimal government policy}

It is easy to see ${ }^{11}$ that the optimal value of $g$ is given by

$$
g=\gamma z,
$$

with

$$
\gamma=-\frac{\hat{a} \hat{\omega} \hat{\sigma}_{u}^{2}}{\left(\hat{\omega}^{2} \hat{\sigma}_{u}^{2}+\sigma_{\varepsilon}^{2}\right)\left(\varphi+\hat{a}^{2}\right)} .
$$

We observe that $\gamma$, the degree of stabilization, only depends on the perceived, rather than correct, parameters (with the exception of $\sigma_{\varepsilon}^{2}$ which is common knowledge). The absolute value of $\gamma$ is larger, i.e. there is more stabilization, the less conservative the government (the smaller $\varphi$ ), and the larger the perceived Keynesian multiplier $\hat{a}$, as long as $\hat{a}<\sqrt{\varphi} .^{12}$ However for $\hat{a}>\sqrt{\varphi}$ the converse holds: beyond that threshold an "income effect" dominates, by which less activism is needed to achieve a given level of output stability.

\footnotetext{
${ }^{10}$ Under such an interpretation a greater value of $\varphi$ now means that the government is more "left-wing", under the traditional view that unions are left-wing.

${ }^{11}$ For details, see Saint-Paul (2012b). All the computations for the present paper are in an Appendix available from the author or directly at http://saintpaul.zxq.net/research/Schumpeter\%20lecture\%20appendix\%20computations.pdf

${ }^{12}$ This can be checked by straightforward differentiation of (2).
} 


\subsection{Autocoherence}

A consequence of the government pursuing the optimal policy is that $g$ is colinear with $z$. Therefore, despite that the vector of observables $(y, z, g)$ is three dimensional, we can reduce it to a two-dimensional vector $(y, z)$. This vector is normally distributed with zero mean. Any autocoherent model must replicate the distribution of the observables. This means that if people use this model (under the assumption that it is common knowledge that everybody uses it) in order to predict this distribution, the prediction is correct. Here this means that we must match the variance-covariance matrix of $(y, z)$, that is

$$
\begin{aligned}
\hat{E} y^{2} & =E y^{2}, \\
\hat{E} z y & =E z y, \\
\hat{E} z^{2} & =E z^{2}=1+\sigma_{\varepsilon}^{2} .
\end{aligned}
$$

In those formulas, $\hat{E}$ denotes the mathematical expectation of a variable computed using the perceived model, whereas $E$ denotes the actual mathematical expectation in equilibrium, given that the economy is driven by the actual parameter values while policy is driven by the perceived model.

There are three autocoherence constraints while the perceived model has four free parameters. This leaves one degree of freedom to the economist to choose the perceived model. Computations show that this can be reexpressed as a trade-off between $\hat{a}$ and $\hat{\omega}$ given by

$$
\hat{\omega}=\frac{\varphi+\hat{a} a}{\varphi+\hat{a}^{2}} .
$$

\subsection{The economist's optimal perceived model}

We now turn to the economist's optimal perceived model. Here it is useful to note that policy is reduced to one parameter, the degree of stabilization $\gamma$, and that the economist has one degree of freedom in choosing the perceived model. This means that the economist can induce the value of $\gamma$ that he would pick 
if he were a dictator, that is, the one corresponding to the use of the correct model and the preferences of the economist:

$$
\gamma_{E}=-\frac{a}{\left(1+\sigma_{\varepsilon}^{2}\right)\left(\bar{\varphi}+a^{2}\right)} .
$$

In the sequel, I will label such a situation as "quasi-dictatorship". Equating $\gamma$ to $\gamma_{E}$ and using the autocoherence conditions allows us to compute the perceived model. A central aspect is that it satisfies the following condition:

$$
\hat{a}=a \frac{\varphi}{\bar{\varphi}} .
$$

That is, quite naturally, conservative economists tend to understate the value of the Keynesian multiplier, so as to induce less stabilization. Left-wing economists do the reverse ${ }^{13}$. Furthermore, the gap between the actual and perceived Keynesian multipliers is equal to the preference gap between the economist and the government. If the economist is aligned with the government $(\varphi=\bar{\varphi})$, then the correct model is revealed. Finally, we can also show that a more left-wing economist will (i) understate the sensitivity of the signal to demand shocks $\omega$ (from (3)), (ii) overstate the variance of demand shocks $\sigma_{u}^{2}$, and (iii) understate the variance of supply shocks $\sigma_{v}^{2}{ }^{14}$

Note that if policy were responsive to another driving variable in addition to the demand signal $z$, then the vector of observables would be 6-dimensional. In such a case the economist would not have enough degrees of freedom and would be constrained to reveal the correct model. We will return to that later.

\footnotetext{
${ }^{13}$ Note though that this holds regardless of the value of $a$. It is also be true if $a>\sqrt{\varphi}$, i.e. if the "income effect" dominates. This is because in such a zone the autocoherence condition implies a strong positive link between $\hat{a}$ and $\hat{\sigma}_{u}^{2}$ : that is, any empirically plausible model with a higher Keynesian multiplier must also have a greater variance of demand shocks. The latter, by itself, tends to induce a greater absolute value for $\gamma$. This is the channel through which more left-wing economists induce more stabilization by claiming that $a$ is large, even though the effect of $a$ alone tends to discourage stabilization due to the dominant income effect.

${ }^{14}$ See the computational appendix.
} 


\section{From theory to measurement}

In the preceding discussion, policy is driven by a theory. But policy can be operational only if theory is supplemented by measurement. And, as measurement is costly, one must decide how much resources to allocate to measurement, that is, what to measure and how precisely to measure it. These choices will be driven by theory: Theory will tell us which variables should be measured most precisely because they matter most for policy.

For example, in a vivid account, Bos (2011) illustrates how the Keynesian paradigm influenced the design of national accounts:

The Keynesian type of analysis established a direct link between economic theory and national accounting as both came to use the same macro-economic identities. A direct effect on national accounting was that another definition of national income and product became most popular:(...). Net national income at factor costs was more and more replaced by gross national income at market prices.

The Keynesian type of analysis also threw a new light on the role of the government.(...) This induced the introduction of accounting per sector, in particular the introduction of a government sector.

$(\ldots)$ Keynes $(\ldots)$ clearly saw the importance of national accounting for planning a national economy in times of war as well of peace.

- Bos (2011)

Clearly, different policy paradigms will lead to different measurement strategies. For example, a "libertarian paradigm", based, say, on the ethical system proposed by Nozick (1977), will not pay so much attention to aggregate variables such as GDP or unemployment. Instead, it will attempt to track how well property rights are enforced, and possibly to reconstruct the alllocation of resources 
that would prevail if property rights had been respected in the past, in order to restore this allocation. As another example, recent proponents of paternalist policies based on happiness economics, such as Easterlin (2001) or Layard (2007) will insist on measuring happiness and the importance of behavioural biases instead of, or in addition to, GDP. Indeed the UK government, following those authors, is implementing a system for measuring happiness, which will presumably trigger policy decisions that were not conceivable absent such a system ${ }^{15}$.

The preceding framework delivers some insights about the determnation of macroeconomic theory whenever it is supplemented by public decisions about measurement. In our simple example, we can assume that the government can spend resources in order to better measure the demand shock. Let us assume that one can pick the variance of the noise to the signal $z, \sigma_{\varepsilon}^{2}$, provided one pays a $\operatorname{cost}^{16} c^{2} / \sigma_{\varepsilon}^{2}$. That is, the government's objective function is now $\min E\left(y^{2}+\varphi g^{2}\right)+c^{2} / \sigma_{\varepsilon}^{2}$, while that of the economist is $\min E\left(y^{2}+\bar{\varphi} g^{2}\right)+c^{2} / \sigma_{\varepsilon}^{2}$.

Hence, we now treat $\sigma_{\varepsilon}^{2}$ as policy parameter set by the government prior to the realization of the equilibrium (which is consistent to our prior assumption that it is common knowledge). This means that if we denote by $U\left[\varphi, \gamma, \hat{a}, \sigma_{\varepsilon}^{2}\right]$ the utility of the government as a function of its preference parameter, its stabilization policy, its beliefs, and its measurement policy, the latter will satisfy the following first-order condition:

$$
\frac{\partial}{\partial \sigma_{\varepsilon}^{2}} U\left[\varphi, \gamma, \hat{a}, \sigma_{\varepsilon}^{2}\right]=0 .
$$

We can check that this FOC is equivalent to

$$
\left(\varphi+\hat{a}^{2}\right) \gamma^{2}=\frac{c^{2}}{\left(\sigma_{\varepsilon}^{2}\right)^{2}}
$$

\footnotetext{
${ }^{15}$ See for example http://www.guardian.co.uk/news/datablog/2011/jul/25/wellbeinghappiness-office-national-statistics

${ }^{16}$ Given the Gaussian structure of the model, one would face an identical problem if, in the fashion of Sims (2003), one faced a cost expressed in terms of the mutual information between the signal $z$ and the shock $u$.
} 
Using (2) and the autocoherence conditions we can re-express the optimal measurement as a function of the perceived Keynesian multiplier only:

$$
\frac{\sigma_{\varepsilon}^{2}}{1+\sigma_{\varepsilon}^{2}}=\frac{c(\varphi+\hat{a} a)}{\hat{a} \sqrt{\varphi+\hat{a}^{2}}}
$$

The RHS is increasing in $\varphi$ : More conservative governments invest less in measuring the demand shock because they are less keen on stabilizing the economy ${ }^{17}$. It is also decreasing in $\hat{a}$ : The greater the perceived Keynesian multiplier, the more we want to stabilize and the more we want to measure the demand shock ${ }^{18}$. Also, from (2) we also know that $\gamma$ is larger in absolute value, the smaller $\sigma_{\varepsilon}^{2}$. This is fundamentally because the cross-partial $\frac{\partial^{2} U}{\partial \gamma \partial \sigma_{\varepsilon}^{2}}$ is positive and it is a quite general property of Bayes' law: the lower the noise, the more sensitive our inference is to the signal, and therefore the more we react to the signal. As a result, there exists a measurement multiplier for any change in the perceived model. For a given $\sigma_{\varepsilon}^{2}$, stabilization policy becomes more active whenever the perceived Keynesian multiplier $\hat{a}$ goes up. But this also induces greater efforts at measuring the demand shock, which leads the government to stabilize even more.

In general the economist would like the government to pursue a different level of measurement. The economists' optimality condition for $\sigma_{\varepsilon}^{2}$ is

$$
\frac{\sigma_{\varepsilon}^{2}}{1+\sigma_{\varepsilon}^{2}}=\frac{c \sqrt{\bar{\varphi}+a^{2}}}{a}
$$

Suppose the economist is a conservative, i.e. $\bar{\varphi}>\varphi$. Then he would like to spend less resources on measurement should the government use the correct model. But, at the same time, the economist convinces the government to use too small a Keynesian multiplier, which in itself leads to undermeasurement of the demand shock. We therefore have two conflicting effects: The government

\footnotetext{
${ }^{17}$ This is true provided $\varphi / 2+\hat{a}(\hat{a}-a / 2)>0$, which generally holds as long as $\hat{a}$ is not too small or $\varphi$ not too small.

${ }^{18}$ This is because $\gamma$ always increases with $\hat{a}$, even for $\hat{a}>\sqrt{\varphi}$, once one takes into account all the autocoherence conditions.
} 
is more left-wing than the economist (the preference effect), but has a more right-wing view of the world than it really is (the belief effect), precisely due to the influence of the economist.

Which effect dominates? Suppose the economist sets the perceived model optimally as above, taking the government's measurement policy, i.e. the value of $\sigma_{\varepsilon}^{2}$, as given. This would be the case in a Nash equilibrium where the government sets $\gamma$ and $\sigma_{\varepsilon}^{2}$ while the economists sets the perceived model simultaneously. Then again (5) will hold and substituting into (6) we now have

$$
\frac{\sigma_{\varepsilon}^{2}}{1+\sigma_{\varepsilon}^{2}}=\frac{c\left(\varphi \bar{\varphi}^{2}+a^{2} \varphi \bar{\varphi}\right)}{a \varphi \sqrt{\varphi \bar{\varphi}^{2}+a^{2} \varphi^{2}}}
$$

The RHS can be shown to be larger than that of (7) for $\bar{\varphi}>\varphi$. This means that at the perceived model derived in the preceding section, the government will spend too few resources on measurement compared to what the economist would do if he were a dictator. That is, the belief effect dominates the preference effect. Consequently, if the economist takes this into account when setting the perceived model, he will try to mitigate it by reporting a Keynesian multiplier closer to the truth. This will occur, for example, in a Stackelberg equilibrium where the economist first selects the perceived model and the government then determines the stabilization level $\gamma$ and the precision of the demand signal. Therefore, that an underreported Keynesian multiplier generates a downward bias in measurement will bring the perceived model closer to the correct one. Note though that if instead the preference effect dominated, then the opposite would be true: The economist would be even more biased so as to reduce (if he is conservative) the resources spent on measuring the demand shock, in addition to inducing less stablization. 


\section{Intellectual competition}

The assumption that beliefs are set by a single, highly influential intellectual is obviously quite stark, although it may capture some specific historical period, like the pre-1972 macroeconomic policy paradigm which was heavily influenced by Keynesian ideas, the import substitution model of economic development which was popular in Latin America ${ }^{19}$, or the case of highly ideological totalitarian regimes such as the Soviet Union. In many other cases, though, economists (and other social scientists) inevitably differ in their views. There are different schools of thought with different followers, and these schools of thoughts compete for scientific recognition and influence over policies and outcomes.

We can use the above framework to analyze the role of competing theories. In the same logic as above, I am going to assume that, in any equilibrium, any theory which is believed by some people is capable of explaining the data. This is a natural generalization of the autocoherence property. Again, that several theories may explain the same data is possible because the model is underindentified, and it implies that in any equilibrium, all theories are equally good. In other words, competition for scientific recognition has eliminated all the theories that do not explain the data. What remains is the attempt by each school to influence outcomes through the design of their theory. This influence comes from the fact that each theory is followed by a number of people, or equivalently has a certain "weight", and these respective weights are reflected in the average belief of society, which we can approximmate as an average of the different schools' models. That is illustrated on Figure 3 in the case of two schools, on which I will henceforth focus. There are two theories, represented by points 1 and 2 . Society believes in some average model A, which reflects the weight of each theory - as these weights vary, the average model lies on some "contract curve" S. The greater the weight of theory 2, the closer A will be to 2 on S. Given that average belief, there is an average action which determines

${ }^{19}$ See Dosman, ed. (2006) 
the equilibrium. In that equilibrium, the set of identified models is IM(A). Any theory that survives must lie on $\operatorname{IM}(\mathrm{A})$. Note that the average model itself will not generally be consistent with the data - it is off $\operatorname{IM}(\mathrm{A})$. The "average model" is just a short-cut to represent how beliefs are aggregated between the different schools; there is nobody who actually uses it and therefore it does not have to explain the data.

[FIGURE 3 HERE]

More specifically, in the preceding example, each school $i$ would have a theory summarized by $\left(a_{i}, \omega_{i}, \sigma_{u i}^{2}, \sigma_{v i}^{2}, \sigma_{\varepsilon}^{2}\right)$, and the equilibrium will be as if the perceived model were $\hat{a}=a_{1}^{\theta} a_{2}^{1-\theta}, \hat{\omega}=\omega_{1}^{\theta} \omega_{2}^{1-\theta}$, and so on. Again we can ask the question: How will the different schools' models depend on their preferences? Instead of autocoherence constraints, each school must now design its model so as to match the data in an equilibrium where people use the average model. Then we can show that instead of the autocoherence trade-off (3) school 1 faces the constraint

$$
\omega_{1}-1=\frac{\omega_{1} \hat{a}\left(a-a_{1}\right)}{\hat{\omega}\left(\varphi+\hat{a}^{2}\right)},
$$

and similarly for school 2 .

\subsection{Polarization}

It is natural to assume that the schools play a Nash equilibrium, i.e. take the other school's model as given. Each school will then set its own model by maximizing its utility subject to the data matching constraints such as (8). Note that the schools do not derive utility from their own model, what they really care about is the average model, since it is the one used by the policy maker when setting the level of public expenditures ${ }^{20}$. Given school 2's model,

\footnotetext{
${ }^{20}$ Again, the "policy maker" is a metaphor for the decision process. There is no agent who believes in model A since it does not explain the data, only the compromise between different factions that have a say in policy leads to the same policy that a unitary government with the same preferences and a belief in model A would choose.
} 
there exists a set of average models that are feasible for school 1 . These are the average perceived models $\mathrm{A}=\left(\hat{a}, \hat{\omega}, \hat{\sigma}_{u}^{2}, \hat{\sigma}_{v}^{2}, \sigma_{\varepsilon}^{2}\right)$ such that there exists a model for school $1 \mathrm{~A} 1=\left(a_{1}, \omega_{1}, \sigma_{u 1}^{2}, \sigma_{v 1}^{2}, \sigma_{\varepsilon}^{2}\right)$ such that $\hat{a}=a_{1}^{\theta} a_{2}^{1-\theta}$, etc, and $\mathrm{A} 1 \in$ $\operatorname{IM}(\mathrm{A})$. Figure 4 shows how to construct the locus of feasible average models $\mathrm{FM}_{1}$ for school 1. Any such model must be on the contract curve between the two schools, at a location corresponding to their respective weights, and at the same time school 1 must lie on the locus of identified models in the corresponding equilibrium. (Note that this also need to be true for school 2 in equilibrium, but not necessarily for a deviation considered by school 1, a point to which we return later). This feasibility locus represents the set of average beliefs that school 1 can elicit by appropriately choosing its own theory, given school 2's theory.

[FIGURE 4 HERE]

In principle, then, the economy could be at an equilibrium such as the one depicted on Figure 5, where the feasibility loci intersect, and each scool's indifference curve is tangent to its own feasibility locus.

[FIGURE 5 HERE]

In fact, such an equilibrium is unlikely to arise. To see this, consider for example what would happen if instead of two schools we had a continuum of schools, each with an infinitesimal influence. Then in (8), the average perceived model, captured by the parameters $\hat{a}$ and $\hat{\omega}$, changes only infinitesimally as a given school's model changes. Therefore, the parameters $\hat{a}$ and $\hat{\omega}$ are now treated as fixed by each school, meaning that they all face the same tradeoff between $a_{1}$ and $\omega_{1}$, implying also that they face the same feasibility locus. In other words, everything takes place as though the two curves on Figure 5 coincide. But, since different schools have different preferences, the same aggregate perceived model cannot be optimal for them. If the feasibility loci coincide, an equilibrium where all schools have their indifference curve tangent 
to their feasibility locus at the average perceived model cannot arise. In a similar fashion, getting back to the two schools case, we can consider what happens if their preferences differ marginally from those of the government, that is $\varphi_{1} \approx \varphi_{2} \approx \varphi$. In such a situation, it is natural to assume that they will choose models that also marginally differ from the truth. A first-order apprroximation of (8) around the correct model (i.e. around $\hat{a}=a$ and $\hat{\omega}=1$ ) is

$$
\omega_{1}-1=\frac{\omega_{1} a\left(a-a_{1}\right)}{\varphi+a^{2}} .
$$

This formula tells us that at a first-order approximation, the trade-off between $\omega_{i}$ and $a_{i}$ does not depend on the average perceived model. This is because the deviation between the average perceived model and the correct model only has second order effects. Since the correct model is the same for both schools and independent of their perceived models, they again face the same trade-off between $\omega_{i}$ and $a_{i}$, as in the case with a continuum of schools. This again rules out an interior equilibrium where the average perceived model is optimal for both schools.

What do we, then, expect to observe? In equilibrium, each school will try to choose a corner solution, that is a point on the common feasibility locus which is as extreme as possible. For example school one will pick a theory with the largest possible value of $a_{1}$, while school 2 will pick a theory with the smallest possible value of $a_{2}$. In other words, intellectual competition between schools of thought who try to influence outcomes generates polarized views. The reason is that they are trying to manipulate the same average perceived beliefs and have different targets for those. This is very similar to a game where each player announces a number between 0 and 100 and each derive utility from the average of these two numbers. As long as the two players have different preferences about that average, the Nash equilibrium is such that one player announces 0 and the 
other announces 100. This is true even though their preferences may be quite close: we expect to observe polarized views among economists who may in the end only marginally differ in their preferences.

Such polarized views are not unseen. During the early nineties, the controversies between "fresh water" and "salt water" macroeconomists were polarized: the former emphasized the role of supply shocks in business cycles considerably, while the latter were very dismissive about such views ${ }^{21}$. Similarly, the recent multiplier controversy is arguably polarized, with prominent economists being in favor of either "large" (i.e. 2) or "small" (i.e. 0.5) multipliers, with few views in the middle ${ }^{22}$.

Note however that here we reach the limits of the assumption that the intellectuals are naively believed by their followers. Even if one does not have the required knowledge to reverse engineer their statements, the mere observation of polarized views indicates to the policymakers that they are being manipulated. This surely puts limits on the degree of polarization that one should observe, but to know more about that we would need to work with a more complex model where the policymakers could detect manipulation despite not knowing the correct model nor the experts' preferences, which would open the door for an economist with a less extreme model to enter the market and steal followers from the extremists. On the other hand, we may also explore the idea that extreme views may survive because they are more parsimonious and because they generate more clear-cut prescriptions for actions.

\subsection{Mutation-proofness and consensus}

A general theme of the approach I am discussing is that variation in policy regimes generally change the equilibrium, which increases the amount of data

\footnotetext{
${ }^{21} \mathrm{An}$ account of these controversies can be found in Blanchard (2009), who also notes their tendency to erode over time and for consensus to emerge.

${ }^{22}$ See Batini et al. (2012). Intuitively, a crisis leads people to dismiss previous data; this increases the degrees of freedom of the intellectuals, and therefore the scope for controversy.
} 
that any acceptable model has to explain: such a model now has to replicate the relevant moments for each policy regime. Consequently, the set of autocoherent models is reduced: changes in policy regimes act as a natural experiment which increases the number of parameters that are identified. I will discuss these issues to a greater extent in the next section, but they are also relevant to intellectual competition.

When a school considers deviating and picking a different model, it faces the constraint that its alternative model must explain the data, taking into account that as a result of its deviation, the equilibrium will change due to changes in average beliefs. But this change in equilibrium will then typically make the models of other schools invalid, and our school can very well live with that ${ }^{23}$. This means that by deviating, any school, by changing average beliefs, can force a "natural experiment" that would invalidate the other schools' models. This is somewhat problematic for our equilibrium concept, because then there is no reason why, upon my deviating, my competitors' models should be continue to be believed.

This suggests that it makes sense to consider "mutation-proof" strategies, that is to impose that any theory explains the data regardless of the beliefs promoted by competing theories. This is a strong restriction because it does not restrict the competing theories to be mutation proof themselves; that is, it allows for my competitors to hold demonstrably false views, assuming that they are charismatic enough to nevertheless have followers. It would be interesting to relax such a strong concept of mutation proofness, but here it is enough to illustrate my point.

We can rewrite Equation (8) as

$$
\omega_{1}-1=\frac{\omega_{1}\left(a_{1}^{\theta} a_{2}^{1-\theta}\right)\left(a-a_{1}\right)}{\left(\omega_{1}^{\theta} \omega_{2}^{1-\theta}\right)\left(\varphi+\left(a_{1}^{\theta} a_{2}^{1-\theta}\right)^{2}\right)} .
$$

\footnotetext{
${ }^{23}$ Note however that if it takes into account the consequences of a competing school being abandoned as a result of its own deviation (such as more people adopting its own model), it will pick a different model since the set of feasible average perceived models is changed.
} 
In a mutation-proof equilibrium, this has to hold for any competing model $\left(a_{2}, \omega_{2}\right)$, not just for the equilibrium one. Clearly, this can be the case only if $a=a_{1}$ and $\omega=\omega_{1}$. The correct model must now be reavealed.

More generally, though, it may be that mutation-proofness does not yield enough constraints to force to reveal the correct model. In such cases it will induce the economist to reveal some parameters (or perhaps a combination of parameters), while at the same time the tendencies for polarization on other parameters will remain. Thus we see how intellectual competition generates forces towards polarization as well as consensus, although here consensus arises over the correct model, because mutation proofness compels the schools to come up with more robust theories, rather than out of a need to conform to the views of others.

\section{Degenerative research programs}

In the preceding discussion, I implicitly assumed that the correct model's specification was common knowledge, by imposing that any perceived model should have the same structure as the correct one and differ from it only because it has different parameter values. But of course in reality the correct specification is unknown, so that a self-serving expert could pick his specification so as to preserve or achieve influence. Indeed, a measure of the degree of influence is

$$
I=A-B-C,
$$

where $A$ is the number of independent parameters of my model, $B$ is the number of autocoherence conditions, and $C$ the number of policy parameters set by the government. Generally, if $I \geq 0$, the expert is a quasi-dictator. On the other hand, if $I \leq-C$, the expert is forced to reveal the correct model.

Let us go back to the remark, made in the preceding section, that policy regime changes generate new observations that make it more difficult for my 
model to match the data. This means that we expect $B$ to increase each time there is a regime change. Let us hold $A$ and $C$ fixed. If regime changes happen with a non zero probability, if there is an arbitrarily large number of potential policy regimes, and if one does not forget the data, then at some point $I$ will fall to $-C$ and the expert's influence will vanish.

However, if we now assume that the correct value of $A$ is not know, there is now a natural way for the expert to preserve his influence, by making the model more complex, i.e. by adding parameters, so that $A$ could increase over time in line with $B$. In a dynamic fashion, the expert's model could be rejected after a policy regime change (or any other natural experiment), and he would come up with a more complicated model that would explain the new data in addition to the old ones. One may wonder why anydoby would still believe him, rather that say a competitor. However it does not really matter to us whether we are talking about the initial expert or a competitor, as long as the competitor is also self-interested and has to come up with an equally complex model in order to explain the data.

Therefore we expect self-interested experts to make their model more complex over time in order to preserve influence. This is similar to the notion of a degenerative research program discussed by Lakatos (1978), a follower of Kuhn (1962). The distinction between progressive and degenerate research programs, according to Lakatos, is summarized in Table 3.

[TABLE 3 HERE]

\subsection{A simple example}

Let us illustrate this point in the context of our simple framework. In our model, part of the reason why the government does not know the correct Keynesian multiplier is that according to its beliefs it is pursuing an optimal stabilization policy, by which public expenditures are colinear with the signal $z$. Suppose we 
are in a situation such as the one described in section 3, with the perceived model set by an interested expert, and that there is now an exogenous, random source of variation in public expenditure, such aa a war, a natural disaster, and so forth. Then the total amount of public expenditure is now equal to

$$
g=x+\eta
$$

where $x$ is the discretionary spending component and $\eta$ is the noise. Again I assume that it is common knowledge that the variance-covariance matrix of $(u, v, \varepsilon, \eta)$ is diagonal. The government now only controls $x$ and cannot offset the noise $\eta$. It is clear that it is optimal for the government to set $x$ at the same level as it was setting $g$ in the absence of noise, that is $x=\gamma z$, with $\gamma$ given by (2). The novelty, though, is that $g$ is no longer colinear with $z$. Any autocoherent model must match the variance-covariance matrix of $(y, z, g)$, which implies 6 restrictions, while the model only has five parameters. Therefore, in this new regime, the correct model typically has to be revealed. Indeed, reducing again the analysis to $\hat{a}$ and $\hat{\omega}$, it can be checked that instead of one trade-off between these two perceived parameters, we now have two, which can be written $\operatorname{as}^{24}$ :

$$
\begin{aligned}
\gamma\left(1-\frac{1}{\hat{\omega}}\right) & =\left(\gamma^{2}\left(1+\sigma_{\varepsilon}^{2}\right)+\sigma_{\eta}^{2}\right)(\hat{a}-a), \\
1-\frac{1}{\hat{\omega}} & =\gamma\left(1+\sigma_{\varepsilon}^{2}\right)(\hat{a}-a) .
\end{aligned}
$$

The first trade-off derives from the autocoherence condition $\hat{E} y g=E y g$, and the second one derives from $\hat{E} y z=E y z$. It is straightforward to check that for these two conditions to hold it must be that $\hat{a}=a$ and $\hat{\omega}=\omega=1$. It can also be shown that the other correct parameter values, including in particular $\sigma_{\eta}^{2}$, have to be revealed.

Thus it appears that it the new regime, the economist is compelled to reveal the truth. Indeed, if prior to the regime he was promoting an incorrect model, the model would have to be abandoned in favor of the correct one. Given that

\footnotetext{
${ }^{24} \operatorname{In}(10)$ we make use of the restriction that $\hat{\sigma}_{\eta}^{2}=\sigma_{\eta}^{2}$, which is why $\sigma_{\eta}^{2}$ instead of $\hat{\sigma}_{\eta}^{2}$ appears on the RHS.
} 
in any case the preceding model has to be abandoned, though, the economist may consider other options than revealing the correct model that may preserve his influence. In particular, as long as the correct specification is not common knowledge (and there is no reason why it should be since a specification fundamentally is an intellectual construct), the economist can preserve his influence by making the model more complex, that is, by increasing the number of parameters $A$ so as to offset the increase in the number of autocoherence conditions $B$.

Suppose then that upon invalidation of the preceding perceived model in the new regime, the economist now modifies it marginally and claims that the random component of public expenditures has a different multiplier from the systematic one. That is indeed plausible, since under rational expectations surprises generally have different effects from anticipated shocks. That is, output determination is now

$$
y=a x+b \eta+u+v,
$$

where the correct parameter values are such that $b=a$ but the economist can pick $\hat{b}$ different from $\hat{a}$. It is then easy to see that the autocoherence condition (10) becomes

$$
\gamma\left(1-\frac{1}{\hat{\omega}}\right)=\left(\gamma^{2}\left(1+\sigma_{\varepsilon}^{2}\right)+\sigma_{\eta}^{2}\right)(\hat{a}-a)+\hat{\sigma}_{\eta}^{2}(\hat{b}-a)
$$

while the other autocoherence condition (11), i.e. $E y z=\hat{E} y z$, is unchanged, as it does not involve $\hat{b}$ since it is common knowledge that the shocks $(u, v, \varepsilon, \eta)$ are uncorrelated. Furthermore it must still be that $\hat{\sigma}_{\eta}^{2}=\sigma_{\eta}^{2}$, which comes from the fact that $x$ is observed and the variance of $g$ has to be matched. Therefore (12) defines a trade-off between the three perceived parameters $\hat{a}, \hat{b}$, and $\hat{\omega}$. Given a choice for $\hat{a}$ and $\hat{\omega}$ that matches (11), the economist can now freely pick $\hat{b}$ to match (12). Therefore, the economist can preserve his influence by using the new, less parsimonious model and act again as a quasi-dictator.

In fact, it turns out that the economists cannot lie about $b$ : Substituting 
(11) into (12) imples that $\hat{b}=a$. This is not surprising as $\eta=g-x=g-\gamma z$ is observed and a simple regression of $y$ on $\eta$ allows to observe $b$. But by sticking to a specification such that $b \neq a$, the economist can still pick $\hat{a} \neq a$ so as to get his most preferred outcome. In fact, he will report the same keynesian multiplier as prior to the regime change. This is because

(i) the autocoherence condition $\hat{E} z^{2}=E z^{2}$ is unchanged in the new specification and together with (11) which is also unchangedit implies the same trade-off between $\hat{\omega}$ and $\hat{a}$ as in (3).

(ii) Since (2) still holds, so does (4) which is just a special case of (2).

Therefore the economist, when picking $\hat{a}$ and $\hat{\omega}$ so as to equate $\gamma$ with $\gamma_{E}$, will choose the same values as before, and policy will not change. Furthermore, since the economist correctly reports that $\hat{b}=a$, the new perceived model correctly imputes the component of the output variance due to $\eta$, and because of that the autocoherence condition $E y^{2}=\hat{E} y^{2}$ is also unchanged. As a result, $\hat{\sigma}_{v}^{2}$ will also be the same as before.

\subsection{The importance of framing}

One may observe that the new perceived model that preserves the economist's influence is less parsimonious that the correct one. Thus if the policymaker were to choose between the two (say if a competitor proposed the correct model, which matches the data as well as any perceived one in any equilibrium) and the policymaker were to apply Occam's razor, he would pick the correct model. This argument is not very compelling, for two reasons.

First, in general parsimony is not evidence of being correct. Models are supposed to be simplifications of reality, and the simpler the model, the more remote it is from reality. It is true in our example that the more complicated model has no more explanatory power than the simpler one, but since they lead to different policies, the government may reasonably believe that the more sophisticated model indicates a better understanding of reality by the economist 
who proposes it. Furthermore, parsimony may be a way to frame the presentation of an incorrect perceived model so as to make it more credible. For example, suppose there are two parameters, $p$ and $q$ and that only $p+q$ is observed, with $p+q=1$. Suppose a biased economist wants the government to believe that $p=0.95$ and $q=0.05$. In general the economist will have to produce a study showing that these are the correct values, on the basis of some debatable identifying assumption that would deliver those values instead of say $p=0.6$ and $q=0.4$. Arguably the best way to sweep the issue under the carpet would be to adopt a parsimonious specification where one would estimate $p$ to be equal to one while ignoring $q$. This delivers a model which is close to the one preferred by the economist, although not exactly equal to it. By ignoring $q$ the economist is implictly making the identifying assumption that $q=0$ while conveniently not calling attention upon the fact that he is making that assumption. This is more credible than explicitly assuming $q=0.05$ and defending it (an alternative technique is to relegate such identifiying assumptions to some cumbersome appendix at the end of the paper).

Second, and most importantly, if one defines parsimony dynamically in terms of the amount of change that is required, it is not clear that the correct model beats the new perceived one. As we have seen, in the new perceived model, two new paramaters are introduced, $\hat{b}$ and $\hat{\sigma}_{\eta}^{2}$, and the perceived values of all the other parameters are unchanged. On the other hand, if one were to adopt the correct model one would have to change one's views on all the parameters $\left(a, \omega, \sigma_{u}^{2}, \sigma_{v}^{2}\right)$. Once the perceived model is firmly established as a frame of reference, making it more sophisticated at the margin will be more appealing than a paradigm shift. The present discussion shows that such an incremental change is appealing to the intellectual who wants to preserve his influence. But other factors, such as sheer career incentives and cognitive limitations such as difficulties to think "outside the box", will push in the same direction. As a result, of course, the discipline will engage in a degenerative research programme. 
What is key here is that a frame of reference is a set of identifying assumptions. Thus, in the preceding example, the amendment to the existing model - the "discovery" that random shifts in public expenditures have a different multiplier - could rationally be presented as a new finding, as long as it is considered, explicitly or implicitly, that it is "known" that the multiplier for systematic expenditure shifts is equal to $\hat{a}^{25}$. Arnold Kling (2011) expresses his sceptical views about such a process:

"Because of the need to impose strong priors, the structural approach is nothing but a roundabout way of communicating the way you believe the economy works. The estimated equations are not being used to discover relationships. Instead, the equations are being used by the econometrician to communicate to others the econometrician's beliefs about how the economy ought to work. To a first approximation, using structural estimates is no different from creating a simulation model out of thin air by making up the parameters."

Kling (2011).

Kling also describes three main strategies that were used to preserve the dominant paradigm in the face of new contradictory evidence (such as the drift in the Phillips curve): "dropping old data; add factors; and lagged dependent variables.". Clearly the last two practices can be interpreted in light of Lakatos's views regarging degenerative research programme. A similar account of macroeconometric practice can be found in Lucas and Sargent (1979).:

"The track record of the major econometric models is (...) very poor.(...). Moreover, this difficulty is implicitly acknowledged by model builders thelmselves, who routinely employ an elaborate sys-

\footnotetext{
${ }^{25}$ In a similar vein, Lucas and Sargent (1979) describe how the postulates from the General Theory, such as those regarding the demand for money or the consumption function, were systematically used as (unwarranted, in their view) identifying assumptions in structural macroeconometric modelling.
} 
tem of add factors in forecasting, in an attempt to offset the continuing drift of the model away from the actual series."

Lucas and Sargent (1979)

Note that there are other mechanisms for preserving an existing paradigm. For example Cogley and Sargent (2005) argue that the old Phillips curve hypothesis was only discarded by policymakers in favor of the natural rate one in the late 1970s, despite that its likelihood was (in their view) quite low as early as 1970. Their idea, borrowed from Hansen and Sargent's (2005) robust control theory, is that the old Phillips curve view delivered the worst case scenario of a painful disinflation; under robust control, a lot of weght is given to the worst case scenario even though the model that delivers it is unlikely ${ }^{26}$. From our perspective, this suggests that the expert can strategically use the policymaker tendencies toward prudence, by devising a model such that policy deviations from the expert's preferred outcome are very costly, i.e. acting as a doomsayer. Indeed, revising one's model to make it more dramatic may be viewed as one instance of a degenerative research programme.

\section{Conclusion}

A scientific paradigm is necessary to set a framework for scientific progress. Similarly, an economic paradigm is necessary for policy to be conducted. But are economic paradigms neutral or do they reflect an agenda? Here I have explored the latter possibility, on the basis of two stark simplifying assumptions. The first assumption is that the policymaker naively accepts the model presented to him by the economists. The second assumption is that the economist knows the correct model and cynically reports an incorrect (but unfalsifiable) one. The analysis hopefully delivers some interesting insights about how interest groups may affect beliefs even in the case where those are embodied in sophisticated

${ }^{26}$ This view is consistent with the historical account of De Long (1996). 
theories validated by the data. But it leaves many questions open to future research. One will need to relax these two assumptions in order to better understand how people pick the theories they use and how political preferences shape the views of the intellectuals in a sophisticated fashion. Also, we need to understand why some theories (such as the Keynesian one), rather than competing ones, become the dominant paradigm, and why and when a paradigm is eventually abandoned. 


\section{REFERENCES}

Acemoglu, Daron and James A. Robinson (2001), "Inefficient Redistribution", American Political Science Review, Vol. 95, No. 3, pp. 649-661

Alesina Alberto and George-Marios Angeletos (2005). "Fairness and Redistribution," American Economic Review, vol. 95(4), pages 960-980

Batini Nicoletta, Giovanni Callegari and Giovanni Melina, "Successful Austerity in the United States, Europe and Japan", IMF Working Paper, 2012

Bénabou Roland and Efe A. Ok (2001). "Social Mobility And The Demand For Redistribution: The Poum Hypothesis," Quarterly Journal of Economics, vol. 116(2), pages 447-487, May.

Blanchard, Olivier, 2009. "The State of Macro," Annual Review of Economics, Annual Reviews, vol. 1(1), pages 209-228, 05.

Bos, Frits (2011), "Three centuries of macro-economic statistics" Eagle Economic \& Statistics Working Paper 2011-02

Card, David \& Krueger, Alan B, 1994. "Minimum Wages and Employment: A Case Study of the Fast-Food Industry in New Jersey and Pennsylvania," American Economic Review, vol. 84(4), pages 772-93, September.

Cogley, Timothy and Thomas J. Sargent, (2005). "The conquest of US inflation: Learning and robustness to model uncertainty," Review of Economic Dynamics, vol. 8(2), pages 528-563, April.

Crawford, Vincent P. and Joel Sobel (1982) Strategic Information Transmission" Econometrica, Vol. 50, No. 6 (Nov.), pp. 1431-1451

De Long, J. Bradford (1997), "America's Peacetime Inflation: The 1970s," in Christina D. Romer and David H. Romer, Editors, Reducing Inflation: Motivation and Strategy University of Chicago Press (1997)

Dosman, Edgar J., ed. (2006), Raul Prebisch: Power, Principle and the Ethics of Development, Washington DC: IDB-INTAL

Easterlin, R. (2001), "Income and Happiness: Towards a Unified Theory", Economic Journal, 111 (473), 465-84. 
Fudenberg. D. and D.K. Levine (1993) "Self-Confirming Equilibrium" Econometrica, 61 , 523-546.

_ _ _ _ _ _ _ _ - (2009), "Self-confirming equilibrium and the Lucas critique" Journal of Economic Theory 144 issue 6 p. 2354-2371

Hansen, L. P. and T. J. Sargent (2005a). "Robust estimation and control under commitment." Journal of Economic Theory 124, 258-301.

Hayek, Friedrich, (1949), "The Intellectuals and Socialism", University of Chicago Law Review

Kling, Arnold (2009), "Macroeconometrics: The lost history", arnoldkling.com/essays/macroeconometrics.doc

Kuhn, T.S. The Structure of Scientific Revolutions. Chicago: University of Chicago Press, 1962.

Lakatos Imre (1978), The Methodology of Scientific Research Programmes: Philosophical Papers Volume 1. Cambridge: Cambridge University Press

Laroque, Guy and Bernard Salanié, (2000)," Une décomposition du non emploi en France ", Economie et statistique, 331

Layard, Richard, (2007). "Happiness and the Teaching of Values." CentrePiece 18-23.

Lucas, R. and T. Sargent (1979), "After Keynesian Macroeconomics", Federal Reserve Bank of Minneapolis Quarterly Review; spring, 1-16

MacKenzie, Donald (2008), An Engine, Not a Camera. How Financial Models Shape Markets. Cambridge MA: MIT Press

Nozick, R., (1977), Anarchy, State and Utopia. New York: Basic Books

Piketty, Thomas, (1995) "Social Mobility and Redistributive Politics", Quarterly Journal of Economics

Saint-Paul, Gilles (2000), The political economy of labour market institutions. Oxford: Oxford University Press (2012a) "Some properties of autocoherent models", working paper, TSE and CEPR 
- (2012b) "Toward a Political Economy of Macroeconomic

Thinking" in J. Frenkel and C. Pissarides, eds, International Seminar on Macroeconomics 2011 (p. 249 - 284), University of Chicago Press for NBER

(2012c) "The scope for ideological bias in structural macroeconomic models", working paper, TSE and NBER

Sargent, Thomas (2008), "Evolution and Intelligent Design", American Economic Review, 98(1), 5-37

Sims Christopher A., "Implications of rational inattention", Journal of Monetary Economics 50 (2003) 665-690 


\section{Pro State Contra State}

Slack Equilibrium

Adaptive Rational

Expectations expectations

Demand shocks Supply shocks

High Keynesian Low Keynesian

Multiplier Multiplier 


\begin{tabular}{l|l}
\hline Pro & Contra \\
\hline Monopsony & Competition \\
\hline $\begin{array}{l}\text { Low labour } \\
\text { demand } \\
\text { elasticity }\end{array}$ & High labour \\
\hline
\end{tabular}

Table 2 -- Views on the labor market and preferences for high minimum wages 


\section{Progressive $\quad \cdot$ New facts are predicted by the theory \\ - These facts are subsequently confirmed empirically}

Degenerative

- New facts invalidate the existing theory

- Theory made more complex to accommodate the new facts

Table 3 - Progressive vs. Degenerative research programs according to Lakatos (1978) 


\section{$\mathrm{EE}(1)$}

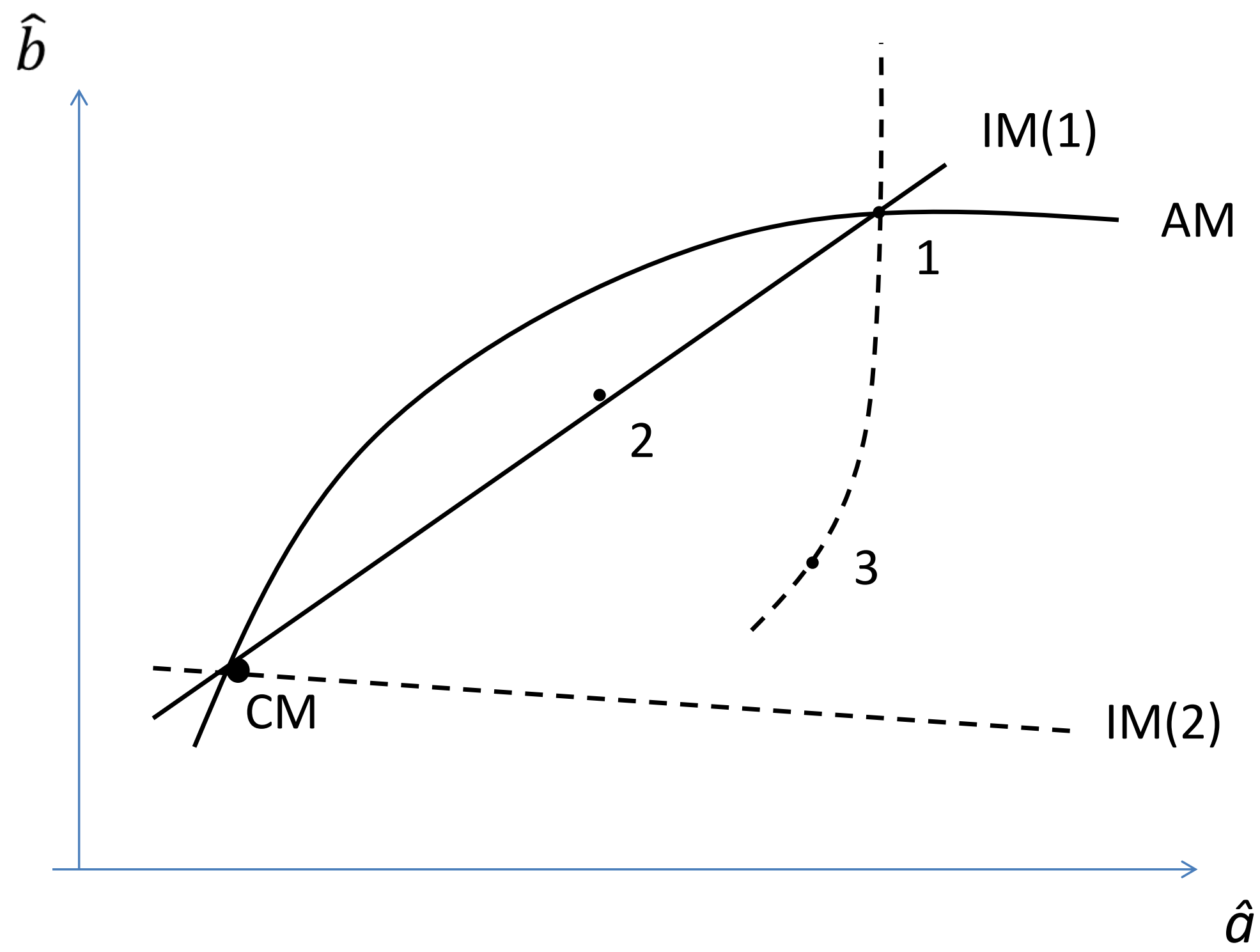

Figure 1 - Autocoherent models 


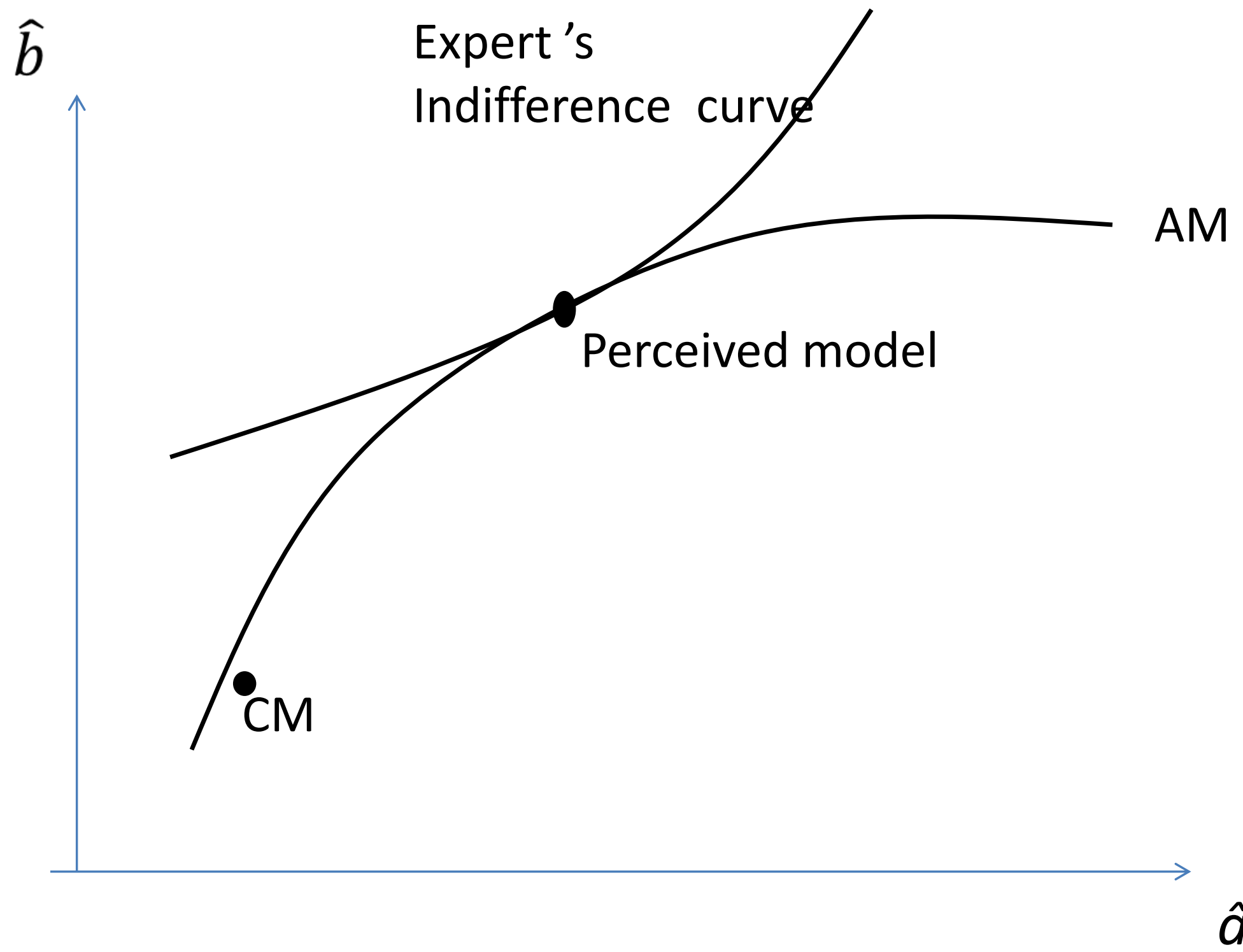

Figure 2-Determination of the perceived model 


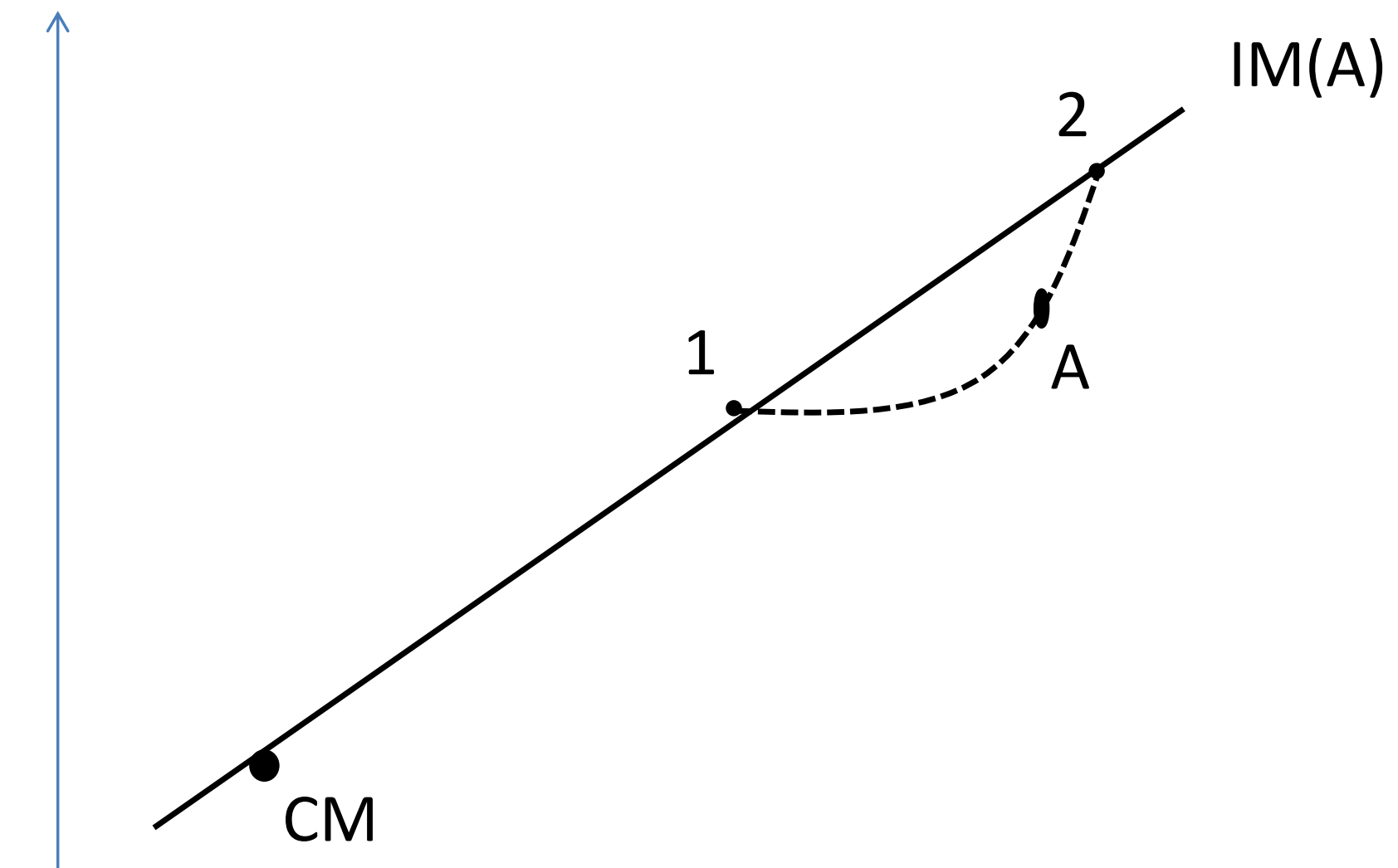

Figure 3 - Two schools of thought 
$\hat{b}$

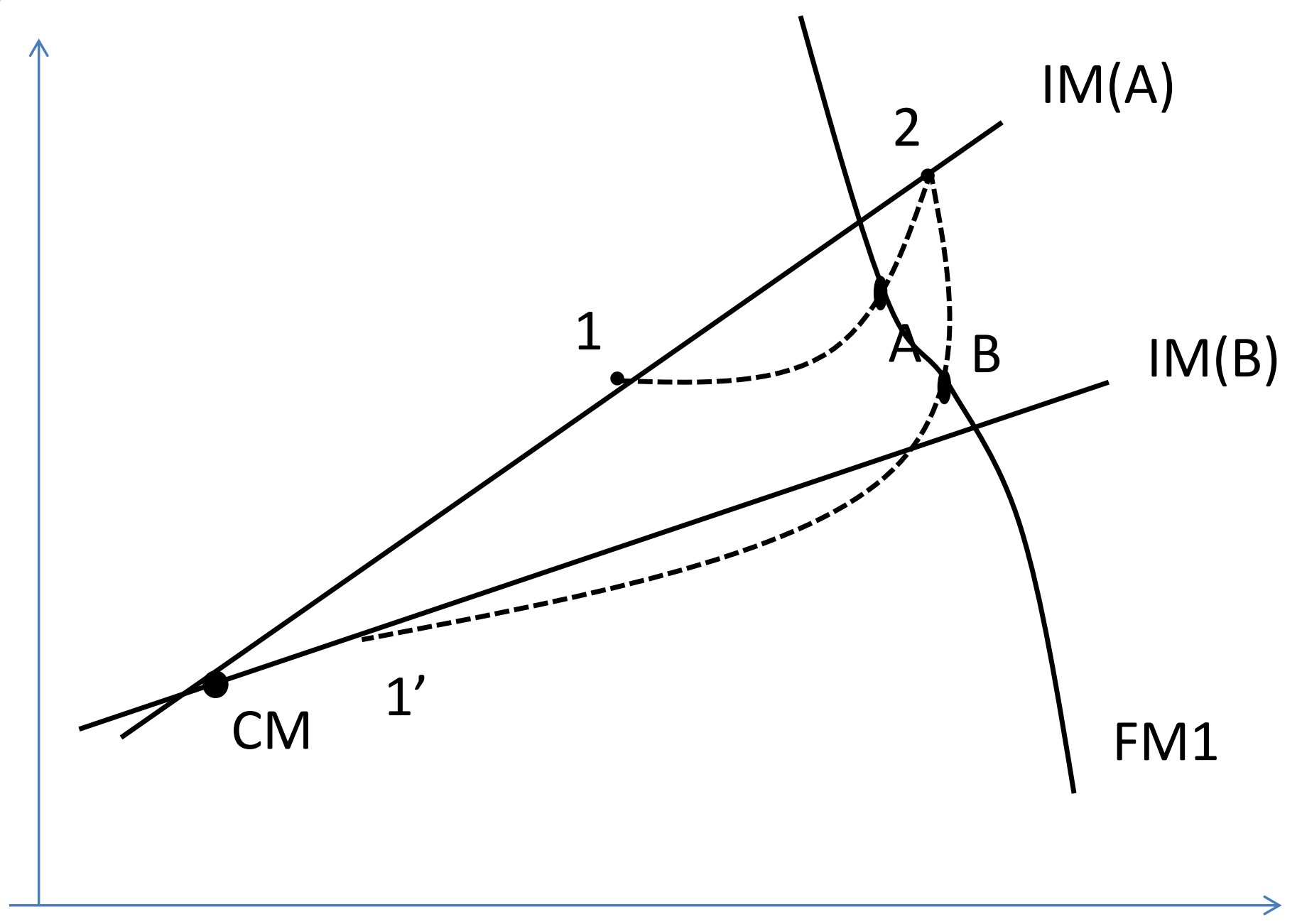

Figure 4 - The feasible average models locus 
$\hat{b}$

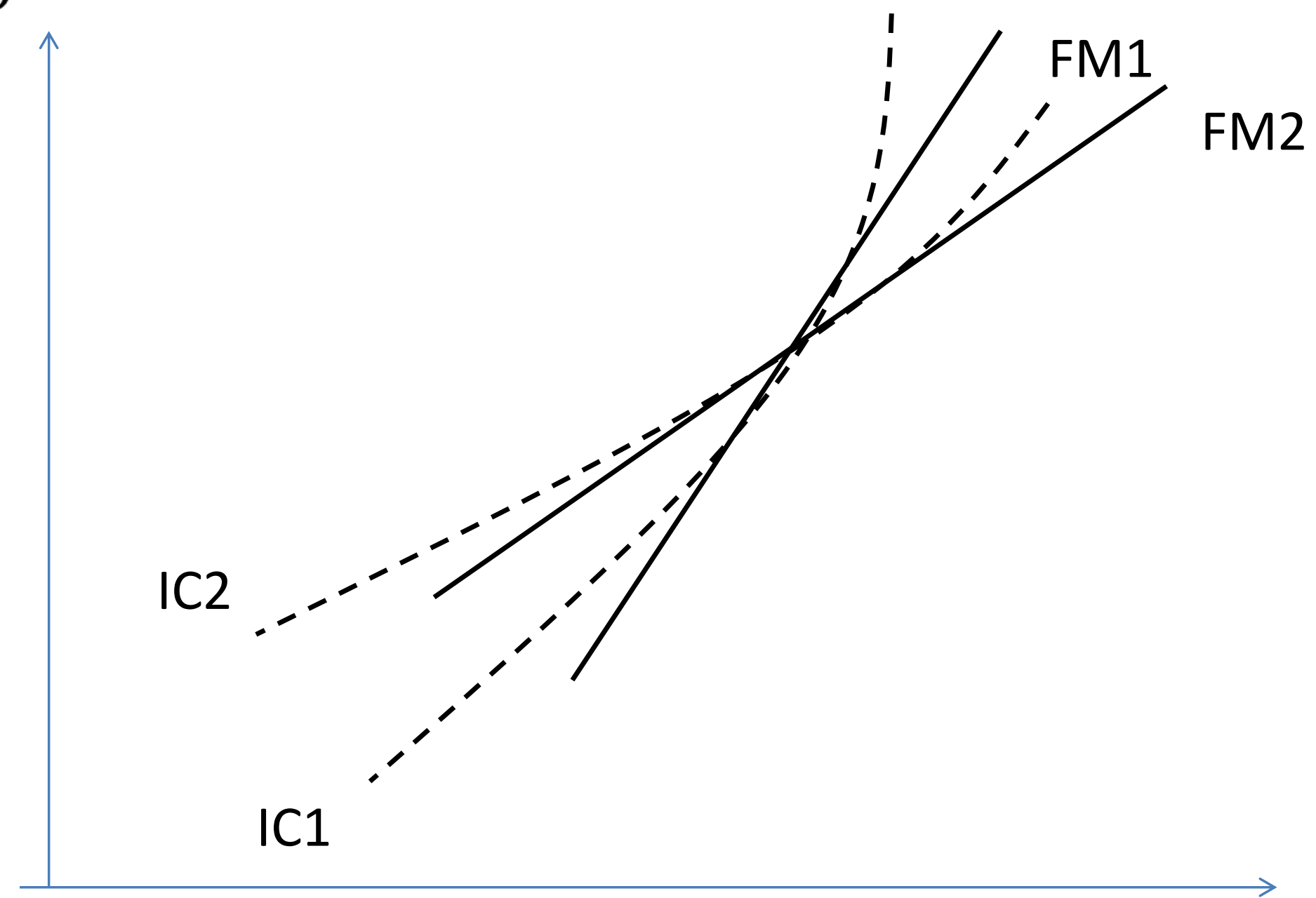

$\hat{a}$

Figure 5 -- Interior equilibrium 